\title{
APLIKASI JAVA PENYEWAAN TENDA USMAN GRUP JAKARTA SELATAN
}

\author{
Muhamad Ruslan', Imam Himawan ${ }^{2}$, Siwi Puji Astuti ${ }^{3}$ \\ ${ }^{1,2,3}$ Teknik Informatika, Fakultas Teknik dan Ilmu Komputer, Universitas Indraprasta PGRI \\ Jalan Raya Tengah No 80, Kelurahan Gedong, Pasar Rebo, Jakarta Timur \\ 1. ruslanmuhamad32@gmail.com, ${ }^{2}$ imamhimawann@gmail.com, ${ }^{3}$ siwiunindra2012@gmail.com
}

\begin{abstract}
ABSTRAK
Usaha pelayanan jasa penyewaan peralatan tenda yang menawarkan berbagai macam produk seperti tenda, sound system, catering, dan dekorasi dari waktu ke waktu mulai berkembang, konsumen biasanya mencari informasi tentang penyewaan jasa peralatan pesta dan mendatangi langsung untuk mengisi formulir penyewaan serta melakukan pembayaran. Tujuan yang dicapai melalui penelitian ini adalah untuk mengetahui apa saja kekurangan yang ada di Tenda Usman Grup, Manfaat penelitian memberikan kemudahan admin untuk data-mendata dengan aplikasi sistem teknologi komputer yang didesain khusus untuk Tenda Usman Grup. Sehingga untuk melakukan pencarian data mengalami kesulitan dan membutuhkan proses yang lamaModel SDLC yang dipakai dalam penelitian ini adalah model Waterfall. Waterfall Model atau Classic Life Cicle merupakan model yang paling banya dipakai dalam Software Enginnering (SE).Membangun sistem informasi yang sudah terkomputerisasi yang dapat membantu kinerja admin dalam pendataan Tenda , Transaksi, pembuatan laporan Masuk dan Keluar dan pembuatan daftar tenda yang sudah selesai Sehingga proses pengolahan data yang ada lebih terkontrol dengan sistem komputerisasi ini sangat memudahkan saat pembuatan laporan dan penyimpanan data dengan harddisk dapat menghemat tempat dan biaya serta terjamin keamanannya karena dapat digunakan berulang-ulang kali dan diperbaharui.
\end{abstract}

Kata Kunci : Tenda Usman Grup, Java, Netbeans

\begin{abstract}
Tent equipment rental service businesses that offer a variety of products such as tents, sound systems, catering, and decorations from time to time began to develop, consumers usually seek information about party equipment rental services and come directly to fill out rental forms and make payments. The goal achieved through this research is to find out what are the shortcomings that exist in the Usman Group Tent. So, to search for data, it is difficult and requires a long process. The SDLC model used in this study is the Waterfall model. The Waterfall Model or Classic Life Cicle is the most widely used model in Software Engineering (SE). Build a computerized information system that can assist admin performance in data collection of Tents, Transactions, making Incoming and Outgoing reports and making a list of completed tents. The existing data processing is more controlled with a computerized system. This makes it very easy when making reports and storing data with a hard disk, it can save space and costs and is guaranteed security because it can be used repeatedly and updated.
\end{abstract}

Key Word: Usman Group Tent, Java, Netbeans

\section{PENDAHULUAN}

Usaha pelayanan jasa penyewaan peralatan tenda yang menawarkan berbagai macam produk seperti tenda, sound system, catering, dan dekorasi dari waktu ke waktu mulai berkembang. Saat ini peminat terhadap penyewaan peralatan pesta semakin meningkat terlihat pada musim acara-acara pesta seperti perpisahaan sekolah, ulang tahun dan acara pesta lainnya, konsumen biasanya mencari informasi tentang penyewaan jasa peralatan pesta dan mendatangi langsung untuk mengisi formulir penyewaan serta melakukan pembayaran. Tenda Usman Grup yang beralamat di Jalan Swadaya 1 Rt.009/Rw.009 Kelurahan Pejaten Timur, Kecamatan Pasar Minggu, Jakarta Selatan, selama ini proses administrasi pelayanan masih menggunakan kegiatan manual. Transaksi penerimaan tenda masih dicatat dalam nota penerimaan tenda. Sehingga untuk melakukan pencarian data mengalami kesulitan dan membutuhkan proses yang lama. Serta untuk mengetahui pendapatan tenda juga harus melakukan rekapitulasi semua nota penerimaan tenda. Selain itu pendataan pembelian barang untuk keperluan Tenda Usman Grup juga masih menggunakan 
pendataan manual sehingga untuk mengetahui jumlah pengeluaran tenda membutuhkan waktu yang relatif lama. Untuk itu penulis membuat sistem informasi agar pencatatan pendapatan Tenda dapat berjalan cepat, efektif, dan efisien. Dari uraian permasalahan di atas, penulis tertarik untuk meneliti lebih jauh tentang proses bisnis jasa penyewaan tenda pesta dan membuat suatu program berbasis java dengan judul "Aplikasi Penyewaan dan Pendataan Tenda Usman Grup Berbasis Java Jakarta Selatan". Aplikasi ini dikembangkan memanfaatkan teknologi informasi berbasis Java, yaitu menggunakan Java Netbeans sebagai bahasa pemrograman dan menggunakan Mysql untuk pengolahan database.

Tujuan yang dicapai melalui penelitian ini adalah untuk mengetahui apa saja kekurangan yang ada di Tenda Usman Grup, sehingga akan memberikan usulan atau jalan keluar agar mencapai hasil yang diinginkan untuk tahun-tahun yang akan datang.

Manfaat penelitian memberikan kemudahan admin untuk data-mendata dengan aplikasi sistem teknologi komputer yang didesain khusus untuk Tenda Usman Grup agar tidak perlu lagi menggunakan buku besar untuk mendata. Serta tidak kehilangan data-data penting dari bulan-bulan atau tahun-tahun sebelumnya dan untuk masa yang akan datang.

\section{METODE PENELITIAN}

Model SDLC yang dipakai dalam penelitian ini adalah model Waterfall. Waterfall Model atau Classic Life Cicle merupakan model yang paling banya dipakai dalam Software Enginnering (SE). Menurut Bassil (2012) disebut waterfall karena tahap demi tahap yang harus dilalui menunggu selesainya tahap sebelumnya dan berjalan berurutan.

1. System / Information Engineering and Modeling

Permodelan ini diawali dengan mencari kebutuhan dari keseluruhan sistem yang akan diaplikasikan ke dalam bentuk software. Hal ini sangat penting, mengingat software harus dapat berinteraksi dengan elemen-elemen yang lain seperti hardware, database, dsb. Tahap ini sering disebut dengan Project Definition.
2. Software Requirements Analysis

Proses pencarian kebutuhan diintensifkan dan difokuskan pada software untuk mengetahui sifat dari program yang akan dibuat, maka penulis harus mengerti tentang domain informasi dari software, misalnya fungsi yang dibutuhkan dalam pembuatan aplikasi. Dari 2 aktivitas tersebut (pencarian kebutuhan sistem dan software) harus didokumentasikan dan ditunjukkan kepada pelanggan.

\section{System Design}

Proses ini digunakan untuk mengubah kebutuhan-kebutuhan diatas menjadi representasi ke dalam bentuk "blueprint" software sebelum coding dimulai. Desain harus dapat mengimplementasikan kebutuhan yang telah disebutkan pada tahap sebelumnya. Maka proses ini juga harus didokumentasikan sebagai konfigurasi dari software.

\section{Implementation}

Implementation Untuk dapat dimengerti oleh mesin, dalam hal ini adalah komputer, maka desain tadi harus diubah bentuknya menjadi bentuk yang dapat dimengerti oleh mesin, yaitu ke dalam bahasa pemrograman melalui proses coding. Tahap ini merupakan implementasi dari tahap design yang secara teknis nantinya dikerjakan oleh programmer

\section{HASIL DAN PEMBAHASAN}

Aplikasi sistem informasi Tenda Usman Grup yang terkomputerisasi sehingga dapat dihasilkan informasi yang lebih cepat, tepat dan akurat:

1. Membangun sistem informasi yang sudah terkomputerisasi yang dapat membantu kinerja admin dalam pendataan Tenda , Transaksi, pembuatan laporan Masuk dan Keluar dan pembuatan daftar tenda yang sudah selesai.

2. Perancangan database sistem untuk penyimpanan data agar lebih efisien dan lebih akurat, serta dapat mengurangi adanya kemungkinan kehilangan data.

3. Pembuatan sistem informasi yang dapat dimengerti oleh semua pihak Tenda Usman Grup.

\section{Dekomposisi $\quad$ Fungsi $\quad$ Sistem yang Diusulkan}

Dekomposisi fungsi dimaksudkan untuk mengetahui gambaran fungsi-fungsi proses dan bentuk masukan serta keluaran yang terdapat pada sistem yang akan dijalankan. 
Berikut ini gambaran dari dekomposisi fungsi sistem:

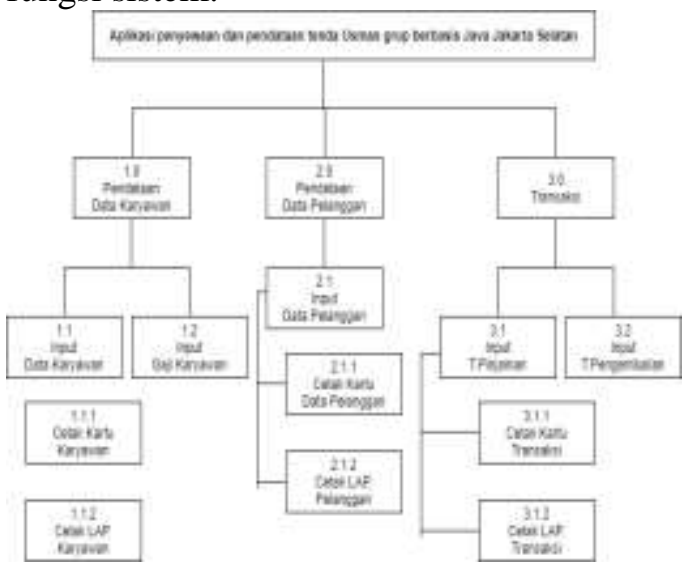

Gambar 1. Dekomposisi Sistem Diusulkan

\section{Diagram Konteks yang Diusulkan}

Aliran data sistem yang diusulkan berikutnya digambarkan pada diagram konteks berikut :

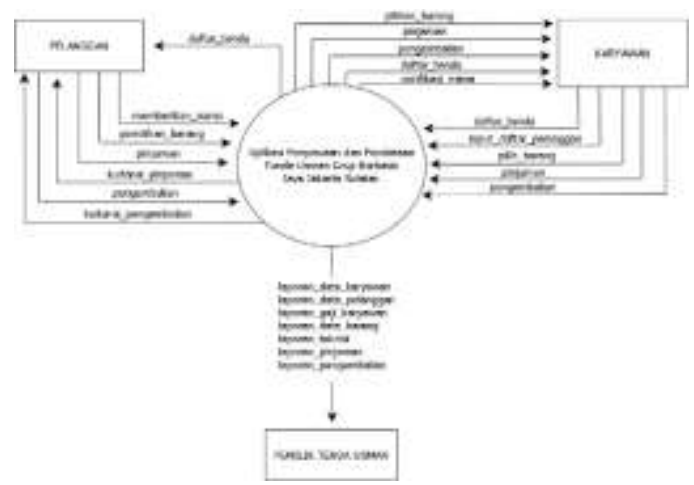

Gambar 2. Diagram Konteks yang Diusulkan

\section{Entity Relationship Diagram (ERD)}

"Entity Relationship Diagram (ERD) adalah suatu model jaringan yang menggunakan susunan data yang disimpan dalam sistem secara abstrak" (Ladjamudin, 2013)

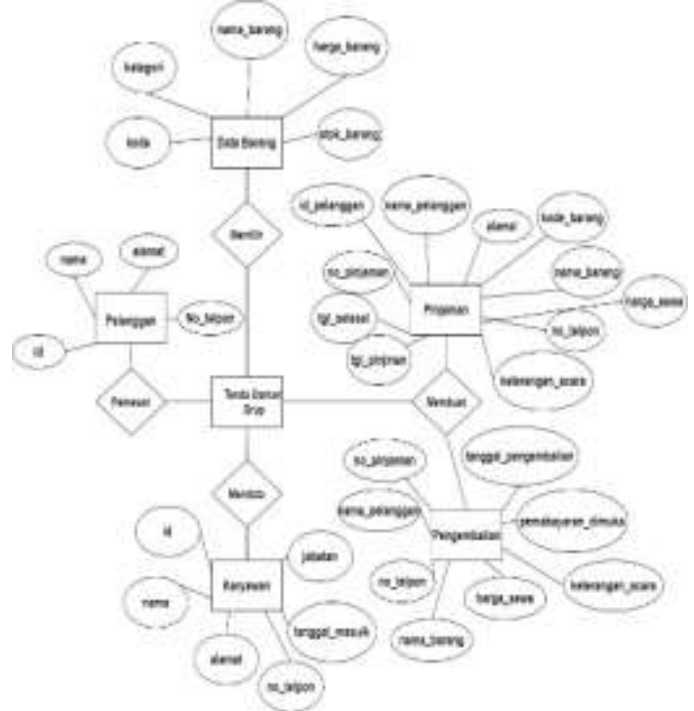

Tampilan Layer Login

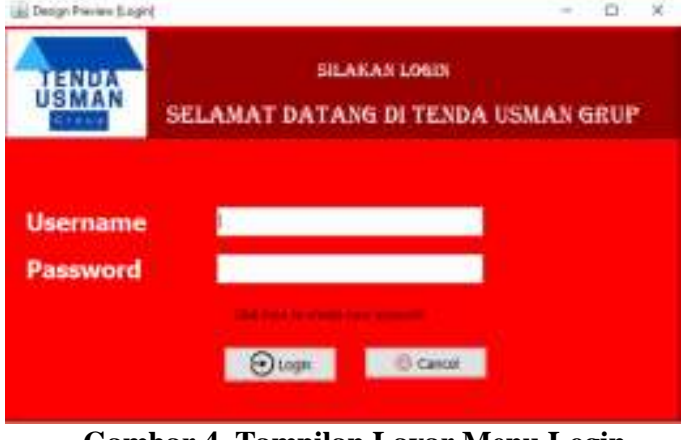

Gambar 4. Tampilan Layar Menu Login

Menu login Admin digunakan sebagai kata kunci sebelum admin memasuki program utama. Menu ini bertujuan untuk mengamankan program supaya tidak dapat diakses oleh orang lain kecuali admin.

\section{Tampilan Layer Menu Utama}

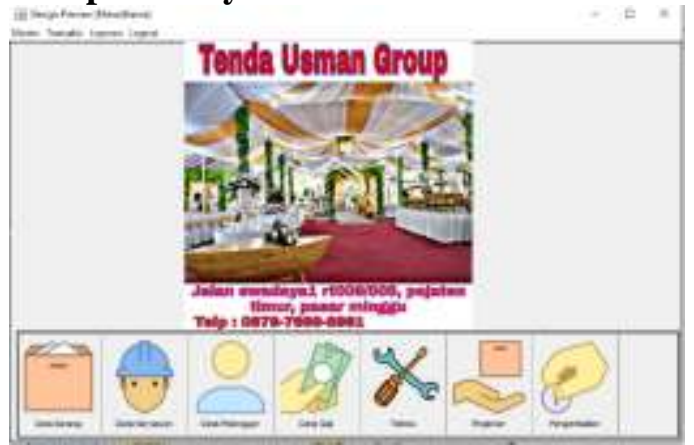

Gambar 5. Tampilan Layar Menu Utama

Menu diatas menampilkan tampilan menu utama sistem informasi pemesanan barang. Menu ini berfungsi untuk memasukkan datadata yang berkaitan dengan Data Barang, Data Karyawan, Data Pelanggan, Data Gaji Karyawan, Teknisi, Pinjaman dan Pengembalian.

\section{Tampilan Layer Data Pelanggan}

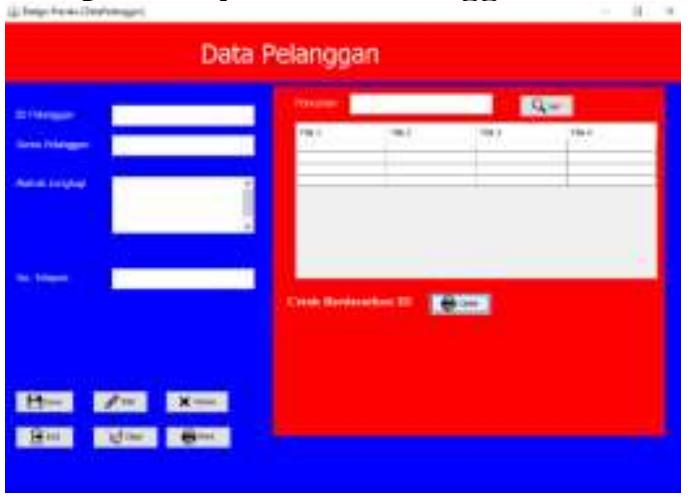

Gambar 6. Tampilan Layer Data Pelanggan Pada Tampilan layer ini admin dapat menginput Data Pelanggan, Melakukan perubahan

Gambar 3. Entity relationship Diagram (ERD) 
Data Pelanggan serta dapat menghapus Data Pelanggan

\section{Tampilan Layer Data Karyawan}

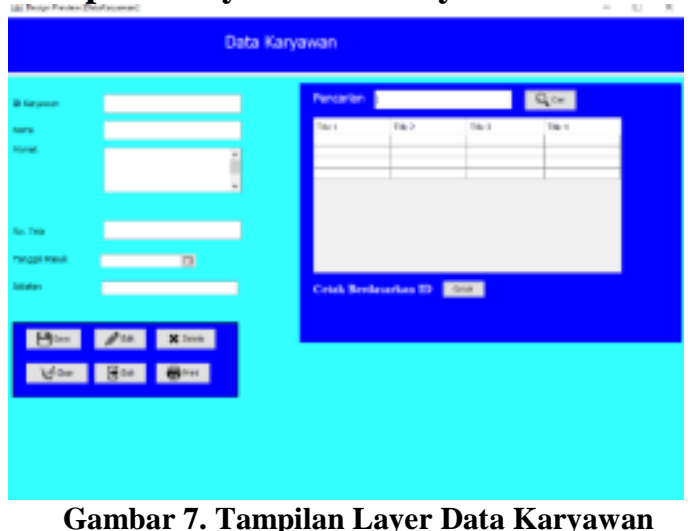

Pada tampilan layer ini admin dapat menginput Data Karyawan , siapa saja yang sudah mulai bekerja dan sudah resmi menjadi karyawan di Tenda Usman Grup

\section{Tampilan Layer Data Barang}

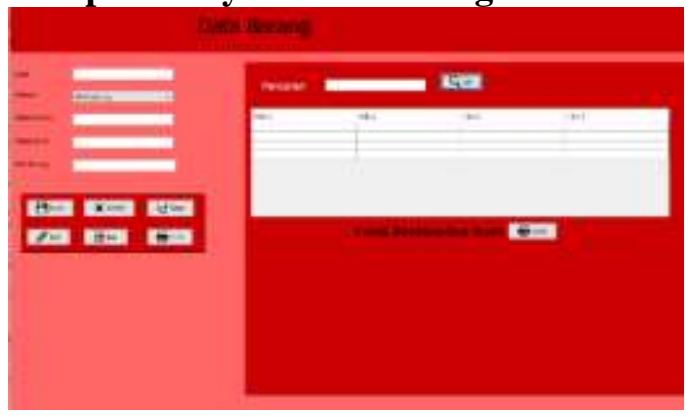

Gambar 8. Tampilan Layer Data Barang

Pada Tampilan layer ini admin dapat menginput Data Barang, Melakukan perubahan Data Barang serta dapat menghapus Data Barang.

\section{Tampilan Layer Transaksi}

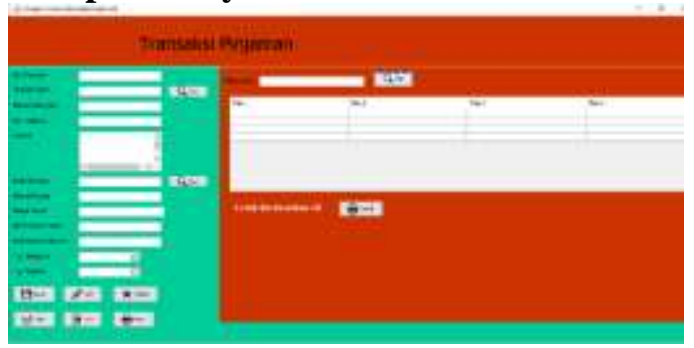

Gambar 9. Tampilan Layer Transaksi

Pada Tampilan layer ini admin dapat menginput Transaksi Pinjaman, Melakukan perubahaan pada Transaksi Pinjaman serta dapat menghapus Transaksi Pinjaman.
Tampilan Laporan Transaksi

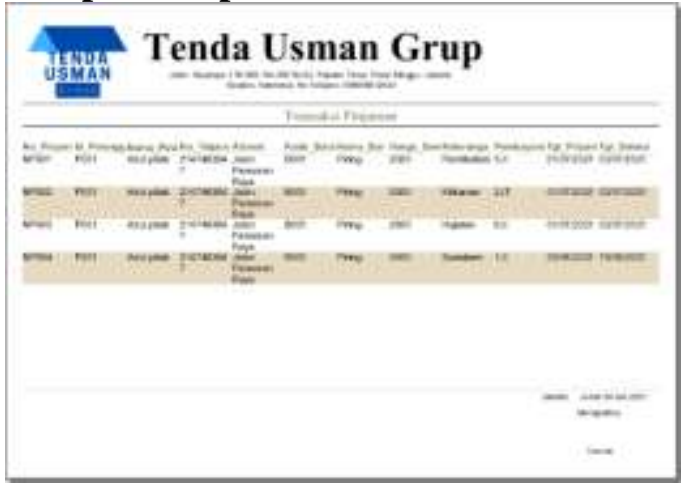

Gambar 10. Tampilan Output Transaksi

Pada Tampilan ini Admin dapat memberikan Laporan Transaksi Pinjaman kepada Pelanggan dan Owner Tenda Usman Grup. Laporan ini bisa muncul setelah melakukan transaksi yang dilakukan pada saat transaksi pinjaman.

\section{SIMPULAN DAN SARAN}

Perancangan sistem Penyewaan dan Pendataan Tenda Usman Grup selama ini masih menggunakan sistem manual, dengan dibuatnya sistem yang baru, yang di rancang menggunakan bahasa pemrograman Java Neatbeans IDE, dengan menggunakan Database MySQL, sehingga pekerjaan lebih efektif dan efisien dalam pengolahan data.

Komputerisasi sebagai alternatif pemecahan masalah dalam menangani masalah-masalah yang terdapat pada sistem Penyewaan dan Pendataan Tenda Usman Grup yang sedang berjalan saat ini diharapkan dapat membantu dan merupakan salah satu alternatif pemecahan masalah. Sehingga proses pengolahan data yang ada lebih terkontrol dengan sistem komputerisasi ini sangat memudahkan saat pembuatan laporan dan penyimpanan data dengan harddisk dapat menghemat tempat dan biaya serta terjamin keamanannya karena dapat digunakan berulang-ulang kali dan diperbaharui.

Saran yang dapat digunakan sebagai bahan pertimbangannya adalah sebagai berikut :

Dalam era globalisasi media komputer sangat dibutuhkan untuk menunjang kemajuan di perusahaan tenda Usman Grup, untuk itu diharapkan dalam penyajian informasi yang cepat dan akurat dan penyimpanan data digunakan sistem untuk mengatasi masalah yang terjadi pada sistem yang berjalan saat ini. 


\section{UCAPAN TERIMAKASIH}

Alhamdulillah puji syukur kepada Allah swt, karena kehendak dan ridha Nya peneliti dapat menyelesaikan pada tepat waktu. Peneliti sadari masih banyak kekurangannya. Adapun dalam kesempatan ini peneliti ingin mengucapkan banyak terima kasih kepada, Bapak Haji Usman selaku pemilik Tenda Usman Grup yang telah mengizinkan penelitian, dan Bapak Dzulfikar Fariz yang telah memberikan bantuan dana untuk penelitian.

\section{DAFTAR PUSTAKA}

Bassil, Y. (2012). A Simulation Model for the Waterfall Software Development Life Cycle. $2(5)$. https://arxiv.org/ftp/arxiv/papers/1205/1 205.6904.pdf

Dedy Rahman Prehanto, D. K. C. (n.d.). Rancang Bangun Sistem Informasi Peralatan Pernikahan Berbasis Web Studi Kasus Cv. Gamalama Wonokromo ( Design Information Sistems For Equipment Wedding With Based Web Case Study In Cv . Gamalama Wonokromo ) Dedy Rahman Prehanto Dessy Kartika Cahyani Abst. 9-17.

Dewi, N. P. (2015). Rancang Bangun Sistem Informasi Persewaan Alat-Alat Pesta Menggunakan Metode Prototype. 1-6.

Ekosari, D. W. (2013). Sistem Informasi Persewaan Alat Pesta Berbasis Web Pada CV. Tri Manunggal Di Ungaran. Sistem Informasi, 13.

Ladjamudin. (2013). Pengertian Erd. Journal Of Chemical Information And Modeling, 142(9), 8-24.

Oliver, J. (2013). Sistem Informasi Penyewaan Peralatan Pesta Pada Saung Kuring Di Cidaun Berbasis Web. Journal Of Chemical Information And Modeling, 53(9), 1689-1699.

Pradipta, A. I. (2016). Rancang Bangun Sistem Informasi Wedding Organizer Di Bandar Lampung Berbasis Android.

Sofiana, S., Kom, S., \& Kom, M. (2020). Perancangan Sistem Informasi Pemesanan Tenda Dan Alat Pesta Pada Bintang Pesta Berbasis Web. 3, 15441550.

Sukma, I., N.A.A, A., \& Henny. (2020). Sistem Informasi Penyewaan Alat Dan Dekorasi Pesta Pada CV. Vira Salon
Berbasis Website. Simkom, 5(1), 1-15. https://doi.org/10.51717/simkom.v5i1.3 9

Zuliananta, M. S. (2020). Perancangan Sistem Informasi Penyewaan Tenda Dan Alat Pesta Pada Medaeng Jaya Berbasis Web. 